\section{Whooping-cough Immunization}

SIR,-It is a little surprising to me that the report of the Public Health Laboratory Service and Working Party (8 November, p. 329 ) concluded that a vaccine which had provided protection against $B$. pertussis types 1,2 , and types 1,2 , and 3 , should have been so relatively unsuccessful in immunizing against types 1,3 . As types 1,3 appeared to be prevalent during the period from which the P.H.L.S. survey was being made, is it possible that something had taken place to interfere with the effectivity of the pertussis fraction of the prophylactic used? The earlier successful official surveys, and my own, were made when the injections given were probably almost entirely a dual antigen of diphtheria and pertussis. Since then the picture has been complicated by the addition of tetanus toxoid and poliomyelitis, the latter either by injection or by mouth.

This now brings us to the interesting question as to how many diseases or antigens the body is equipped or designed to protect itself simultaneously against without failure of one or another immunity response to multiple stimuli. Some ten years ago, in a paper given at a Wellcome symposium before a most distinguished assembly, I suggested that in the use of multiple prophylactics we must be careful not to overload the local immunity mechanism by injecting too much, or too great a variety in one arm. No one questioned this warning note.

I had some reason for giving this warning. Dr. L. B. Holt and I had been investigating the effects of varying the pertussis and tetanus content in mixtures with diphtheria toxoid. ${ }^{1}$ There was some evidence $(P=0.05)$ that excess of tetanus toxoid in a diphtheriatetanus mixture caused a drop in the diphtheria immunity response. Likewise, in a diphtheria-tetanus-pertussis mixture the immunity response to diphtheria was better when the diphtheria-pertussis mixture was given in one arm and the tetanus toxoid in the other. Likewise the adjuvant action of increasing doses of $H$. pertussis in a diphtheria-pertussis mixture was most clearly demonstrated. Admittedly there is only some evidence of tetanus toxoid interference with diphtheria response, but who can say that pertussis immunity cannot be influenced adversely by trying to do too much at a time? Rubella and morbilli have not been mentioned in this discussion, but these might further complicate the picture unless spacing of treatments is carefully considered. I, for one, should not care to see any addition to the usual triple antigen, and I think there is a good case for review of its composition with regard to the dosage of the toxoids.

Finally, if the results of the P.H.L.S. investigation were due to the use of a substandard antigen, could these figures have been better if the other components had not been unnecessarily potent?-I am, etc.,

Broadbridge Heath,

GUY BOUSFIELD.

$$
\text { Sussex. }
$$

\section{Reference} 1 Bousfield, G., and Holt, L. B. British Medical

\section{Unusual Effect of Fenfluramine}

SIR,-I would endorse Dr. I. Oswald's opinion (27 December, p. 806) that fenfluramine is not a central nervous stimulant, and therefore cannot be classed clinically with the amphetamines. In a pilot trial of fenfluramine $(40 \mathrm{mg}$. daily for two weeks, then $80 \mathrm{mg}$. daily for two weeks) in 14 obese patients, who were not told the nature or purpose of the drug, none mentioned a stimulant effect and two reported drowsiness for a few days after starting the drug. Dr. Oswald states that sudden withdrawal after prolonged administration of fenfluramine can be accompanied by temporary mood depression. A few of our patients commented on this and one, who had a previous history of depressive illness, had a severe episode of agitated depression on stopping the drug, which she had taken for four weeks only.

These and other effects of fenfluramine are currently being investigated in a controlled study of this drug in the management of obese patients with rheumatic disorders.-I am, etc,

Princess Alexandra Hospital and Harlow Group, Essex.

SIR,-I was interested to read Dr. S. Brandon's letter (29 November, p. 557) in which he describes an 18-year-old youth with a long history of drug abuse who had been recommended to try Ponderax (fenfluramine) by friends who had used it to obtain a "high." None of the inquiries in which this unit has been engaged, involving both narcotic- and amphetamine-dependent persons, have provided evidence that Ponderax is being abused. While it would be imprudent to conclude that Ponderax is never taken for non-therapeutic reasons, since it is now appreciated that drug addicts typically use a wide diversity of drugs, at the same time it would be unwise to conclude that because a particular drug is taken intermittently by addicts it has been adopted as a drug of abuse.-I am, etc.,

D. V. Hawks.

Addiction Research Unit,
Institute of Psychiatry, Institute of Psych
London S.E.5.

\section{Cost of Medical Publications}

SIR,-Dr. D. A. Pyke (8 November, p 366) asks whether Excerpta Medica ploughs back its profits in some way. Whatever profits are made by Excerpta Medica are, of course, ploughed back into the business as being a foundation it is legally impossible to do otherwise. No one will deny that £22. 0 . 0 . is a high price for the Diabetes publication, to which Dr. Pyke refers. However, we would like to ask Dr. Pyke on what grounds he bases his judgement that it is "too high." We on our side wonder what Dr. Pyke expects the cost of the corresponding volume for the 1970 International Diabetes Congress to be. Neither he nor we yet know how many pages this volume will comprise and, hence, quite obviously a sales price cannot yet be determined. On this subject we can certainly assure Dr. Pykealthough we would not expect such an assurance to be necessary-that the retail price of a book is not calculated on the assumption of a captive audience of medical libraries which may feel obliged to buy the publication.

In the case of Excerpta Medica's abstracting publications, we accord libraries considerable financial advantages in the subscription rates.-I am, etc.,

\section{P. A. WARREN.} Excerpta Medica Foundation.

Amsterdam, Holland.

\section{Mental Illness and the Family Doctor}

SIR,-YYour leading article (13 December, p. 637) and Sir Denis Hill's new monograph $^{1}$ draw attention to "the vast load of neurotic suffering in the community" and "the admitted shortage of trained staff at all levels for coping. . . ."

For many years we have at the Tavistock Clinic been providing seminars for general practitioners in which to study the psychological problems encountered in general practice and now welcome the attention you give to the general lack of appropriate training for these doctors who carry the brunt of the work. On our side, at the Tavistock, we have to think constantly of how to evaluate and improve our methods and approach.

We have on our waiting list a number of doctors waiting to join new seminars on different days and I should be very pleased if it is possible, through your correspondence column, to invite a few more. We could then launch two more seminars shortly.-I am, etc.,

\section{Tavistock Clinic, \\ Tavistock Centre, Belsize Lane,
London N.W.3. \\ REFERENCE \\ 1 Hill. Sir D., Psychiatry in Medicine, London,}

S. BOURNE.

Nuffield Provincial Hospitals Trust, 1969.

\section{Postoperative Fibrinolysis}

SIR,-Prolonged postoperative haemorrhage is usually associated with faulty surgical technique, although a haemorrhagic diathesis may occasionally be to blame. It is known that in heat stroke there is often a disturbance in the blood coagulation mechanism, particularly in the fatal cases. ${ }^{12} \mathrm{Hy}-$ perpyrexia as an abnormal reaction to succinylcholine during anaesthesia has been reported. ${ }^{3}$ A patient is presented here who showed evidence of fibrinolysis, and it is suggested that this may have been the result of a period of hyperthermia during and after anaesthesia.

A 62-year-old female patient presented with lower lumbar backache and right-sided sciatica of seven months' duration. A metabolic study revealed the diagnosis of hyperparathyroidism. It was interesting to note that in 1931 she had presented at the London Hospital with pathological fracture through a bone cyst and that biochemical studies at that time showed hyperparathyroidism. Her abnormal biochemistry in 1931 returned to normal after the removal of a parathyroid adenoma by Sir James Walton. In this respect she was probably the first case of hyperparathyroidism to be diagnosed and successfully treated in this country. She had remained well until the development of her present symptoms. She was regarded as a case of recurrent primary hyperparathyroidism.

Parathyroid exploration was undertaken in July 1969 and a $300 \mathrm{mg}$. adenoma was removed. Anaesthesia was induced with thiopentone 